\title{
Clinical comparison of QOL and adverse events during postoperative adjuvant chemotherapy in outpatients with node-positive colorectal cancer or gastric cancer
}

\author{
MASAYA MUKAI ${ }^{1}$, KYOKO KISHIMA ${ }^{1}$, FUMINO UCHIUMI $^{2}$, EMI ISHIBASHI $^{2}$, MAKI FUKASAWA $^{1}$, \\ TAKAYUKI TAJIMA ${ }^{1}$, MASATO NAKAMURA ${ }^{3}$ and HIROYASU MAKUUCHI ${ }^{4}$
}

${ }^{1}$ Tokai University Hachioji Hospital, Department of Surgery; ${ }^{2}$ Tokai University Hachioji Hospital, Department of Outpatient Treatment, Ishikawa-cho 1838, Hachioji, Tokyo 192-0032; ${ }^{3}$ Tokai University School of Medicine, Department of Pathology;

${ }^{4}$ Tokai University School of Medicine, Department of Surgery, Bohseidai, Isehara, Kanagawa 259-1193, Japan

Received November 25, 2008; Accepted January 27, 2009

DOI: 10.3892/or_00000324

\begin{abstract}
The aim of this study was to evaluate the quality of life (QOL) from the performance status (PS) and face scale (FS), and to compare adverse events (AEs) during chemotherapy in 28 patients with node-positive colorectal cancer (NP-CRC) and 15 patients with node-positive gastric cancer (NP-GC). The anticancer regimen consisted of 5-FU/ $\mathrm{LV}+\mathrm{CPT}-11$ for NP-CRC and 5-FU+low-dose CDDP for NP-GC. Results were evaluated after completion of three courses. QOL evaluation revealed no significant differences between the two groups with respect to PS and FS. Among hematological AEs, grade $1 / 2$ mild leucopenia was significantly more common in NP-CRC than NP-GC patients $(\mathrm{p}<0.05)$, while grade $1 / 2$ mild thrombocytopenia was significantly more common in NP-GC than NP-CRC patients $(\mathrm{p}<0.05)$. Among non-hematological AEs, grade 1/2 mild neuropathy (olfactory nerve) was significantly more common in NP-CRC than NP-GC patients $(\mathrm{p}<0.05)$. The monthly cost for one course was $€ 586.8$ for NP-CRC patients and $€ 181.8$ for NP-GC patients. These results suggest that first-line postoperative outpatient adjuvant chemotherapy for NP-CRC
\end{abstract}

Correspondence to: Dr Masaya Mukai, Tokai University Hachioji Hospital, Department of Surgery, Ishikawa-cho 1838, Hachioji, Tokyo 192-0032, Japan

E-mail: mukai.masaya@hachioji-hosp.tokai.ac.jp

Abbreviations: QOL, quality of life; AEs, adverse events; PS, performance status; FS, face scale; NP-CRC, node-positive colorectal cancer; NP-GC, node-positive gastric cancer; 5-FU, 5fluorouracil; LV, leucovorin; CPT-11, irinotecan; CDDP, cisplatin; FLC, 5-FU/LV+CPT-11; FDP, 5-FU+low dose CDDP; ONCs, occult neoplastic cells; LN, lymph node; TS, thymidylate synthase; DPD, dihydropyrimidine dehydrogenase

Key words: colorectal cancer, gastric cancer, QOL, adverse events, adjuvant chemotherapy, out patients and NP-GC shows no significant differences with respect to QOL, but both AEs and the cost are higher for NP-CRC than for NP-GC.

\section{Introduction}

In recent years, the results of treating primary colorectal cancer and gastric cancer have improved markedly in Japan with the development of surgical techniques and new adjuvant therapy including chemotherapy and radiotherapy. The 5-year survival rate of colorectal cancer patients in stage III/Dukes' C with lymph node metastasis is $60-70 \%$ (colon: $74.0 \pm 3.5 \%$, rectum: $64.7 \pm 4.3 \%$ ) (1-5). For patients with gastric cancer, the 5-year survival rate is slightly less than for those with colorectal cancer, being $50-60 \%$ (stage II: $60-70 \%$, stage III: $40-50 \%$ ) (1-5). In patients undergoing curative surgery, the distant metastasis/ recurrence rates are $\sim 30-40 \%$ for colorectal cancer and $40-50 \%$ for gastric cancer, and recurrence is known to be a life-threatening problem (1-5). Lethal hematogenous metastasis/recurrence to the liver or lungs occurs after curative resection because residual cancer cells circulating in the body during the perioperative period manage to avoid the host's immune defenses. The residual cancer cells find a microenvironment in the liver, lungs, and/or peritoneum that is suitable for adhesion, and then proliferate at this site (6). In particular, there have been many studies on the close relationship to tumor metastasis/recurrence of occult neoplastic cells (ONCs), which are positive for cytokeratin on immunostaining and are found floating in lymph node sinuses distant from the primary tumor (7-10). ONCs are a very small number of malignant cells that can be semiquantitatively assessed by immunostaining and are trapped in the lymph nodes, which are an important part of the body's immune/defense system $(7,8)$. ONCs are found in $>80 \%$ of stage II/III patients with recurrence, while ONC clusters $(\leq 10 \mathrm{ONCs}, \sim 0.2 \mathrm{~mm}$ in diameter) and malignant micro-aggregates (>10 ONCs) consisting of numerous floating ONCs bound together are observed in stage III patients. It has been reported that ONCs should be differentiated from isolated tumor cells (ITCs $\leq 0.2 \mathrm{~mm})$ and micro-metastases $(0.2 \mathrm{~mm}<\mathrm{MM} \leq 2 \mathrm{~mm})$ anchored in the lymph nodes, because ONCs are an occult 
form of systemic metastasis with a higher degree of malignancy (11-13). Therefore, the most important objective of postoperative adjuvant chemotherapy is the eradication of tumor cell clusters and aggregates that circulate in the perioperative period (11-13).

Postoperative adjuvant chemotherapy of node-positive stage III colorectal cancer is performed with combinations of anticancer agents, such as the IFL/FOLFIRI/FOLFOX regimens that contain the topoisomerase-1 inhibitor CPT-11 (irinotecan) and/or the new generation platinum analog LOHP (oxaliplatin), which has a different mechanism of action from 5-fluorouracil (5-FU)/leucovorin (LV) therapy where LV modulates 5-FU. Such regimens show a high level of efficacy and are used as standard treatment (14-16). In the case of node-positive stage II/III gastric cancer, there have been studies on regimens such as 5-FU/LV, 5-FU/low-dose CDDP (FDP), and 5-FU/MTX, but a standard regimen with considerable evidence of usefulness has not yet been established in the same way as for colorectal cancer (17-22). For postoperative adjuvant chemotherapy of gastric cancer in Japan, FDP is more common than 5-FU/LV when the intravenous administration is used. Treatment with S-1 (TS-1: Tegafur, gimeracil/oteracil potassium, Taiho Pharmaceutical Co., Ltd., Tokyo, Japan), a new generation oral anticancer agent, has been recommended and pros-pective randomized trials have been initiated (23-27).

However, no studies have compared the quality of life (QOL) and adverse events (AEs), including safety and tolerance, during first-line therapy with 5-FU/LV+CPT-11 (FLC) vs. FDP as postoperative adjuvant chemotherapy in the outpatient setting after curative resection of node-positive colorectal cancer (NP-CRC) or node-positive gastric cancer (NP-GC) in Japan. Therefore, this study was performed as an overall comparison of postoperative adjuvant therapy with FLC for NP-CRC and FDP for NP-GC. Assessment included the QOL and AEs as well as the cost of treatment.

\section{Patients and methods}

Among patients with primary colorectal cancer or gastric cancer who underwent curative resection in the 5 years from 2000 to 2005,43 patients were enrolled, including 28 patients with stage III; NP-CRC undergoing FLC therapy and 15 patients with stage II/III; NP-GC undergoing FDP therapy. Patients were not older than 75 years and had a performance status (PS) of 0 or 1 . In addition, their medical records had complete details of intravenous chemotherapy and they could be followed to assess metastasis/recurrence and survival. In the FLC group, a modified Machoever's regimen with high-dose 5-FU + high-dose LV was administered once a month over 5 consecutive days (5-FU; $350 \mathrm{mg} / \mathrm{m}^{2}+\mathrm{LV} ; 150 \mathrm{mg} / \mathrm{m}^{2}$ x 5 days/month) for 3-6 months. CPT-11 $\left(60 \mathrm{mg} / \mathrm{m}^{2}\right.$ on day 1 and day 15 of each month $\mathrm{x}$ 3-6 months) was also administered, followed by continuous administration of oral anticancer agents for 1-1.5 years as postoperative adjuvant chemotherapy $(14,28)$ (Fig. 1). The FDP group received 5 -FU $\left(350 \mathrm{mg} / \mathrm{m}^{2}\right)+$ low-dose CDDP (5 mg/m² x 5 days/month) for 3-6 months, followed by continuous administration of oral anticancer agents for 11.5 years $(20-22)$ (Fig. 1). In these two groups, the total number of courses and the mean number of courses were calculated, and evaluation of QOL was done after completion of three courses by determining the PS and face scale (FS). In addition, hematological and non-hematological AEs were examined and the total cost to the patient per course of chemotherapy at the outpatient treatment center based on a national health insurance scheme $30 \%$ co-payment for persons $<70$ years of age, was compared. The hematological parameters subjected to comparison were WBC, RBC, and platelets, while the non-hematological toxicities included nausea, vomiting, anorexia, mucositis, dysgeusia, and neuropathy (cranial-smell). AEs were classified according to the grade of hematological/non-hematological toxicity in each group after completion of three courses of therapy (refer to Japan Clinical Oncology Group/Japanese Society of Clinical Oncology; JCOG/JSCO-CTCAE, version 3.0) and the grades were compared.

Statistical analysis. Comparison of the NP-CRC/FLC group with the NP-GC/FDP group was performed by using the $\chi^{2}$ test and Fisher's test ( $\mathrm{n} \leq 5$ cases), with $\mathrm{p}<0.05$ being taken to indicate a statistically significant difference. Microsoft Office Excel 2003 software (Microsoft Japan Inc., Tokyo, Japan) was used for all of the calculations.

\section{Results}

First, in the NP-CRC group, the total number of courses was 152 and the mean number of courses was 5.4. In the NP-GC group, the total number of courses was 77 and the mean number of courses was 5.1. There were no significant differences between the two groups.

Second, evaluation of postoperative QOL showed that the PS was 0 in 12 patients $(42.9 \%), 1$ or 2 in 14 patients $(50.0 \%)$, 3 in 2 patients $(7.1 \%)$ and 4 in 0 patients $(0.0 \%)$ from the NPCRC group. In the NP-GC group, the PS was 0 in 6 patients $(40.0 \%), 1$ or 2 in 8 patients $(53.3 \%), 3$ in 1 patient $(6.7 \%)$, and 4 in 0 patients $(0.0 \%)$. There were no significant differences between the two groups (Tables I and II). In the NP-CRC group, the FS was grade 0 in 4 patients $(14.3 \%)$, grade 1 or 2 in 22 patients $(78.6 \%)$, grade 3 in 2 patients $(7.1 \%)$, and grade 4 in 0 patients $(0.0 \%)$. In the NP-GC group, the FS was grade 0 in 0 patients $(0.0 \%)$, grade 1 or 2 in 11 patients $(73.3 \%)$, grade 3 in 4 patients $(26.7 \%)$, and grade 4 in 0 patients $(0.0 \%)$. There were no significant differences between the two groups (Tables I and II).

Third, with regard to hematological toxicity, leucopenia was grade 0 in 16 patients $(57.1 \%)$, grade 1 or 2 in 12 patients $(42.9 \%)$, grade 3 in 0 patients $(0.0 \%)$, and grade 4 in 0 patients $(0.0 \%)$ from the NP-CRC group. In the NP-GC group, leucopenia was grade 0 in 13 patients $(86.7 \%)$, grade 1 or 2 in 2 patients $(13.3 \%)$, grade 3 in 0 patients $(0.0 \%)$, and grade 4 in 0 patients $(0.0 \%)$. In the NP-CRC group, grade 1 or 2 leucopenia was significantly more common than in the NP-GC group ( $\mathrm{p}<0.05)$ (Tables I and II). In the NP-CRC group, anemia was grade 0 in 19 patients $(67.9 \%)$, grade 1 or 2 in 9 patients $(32.1 \%)$, grade 3 in 0 patients $(0.0 \%)$, and grade 4 in 0 patients $(0.0 \%)$. In the NP-GC group, anemia was grade 0 in 10 patients $(67.7 \%)$, grade 1 or 2 in 5 patients $(33.3 \%)$, grade 3 in 0 patients $(0.0 \%)$, and grade 4 in 0 patients $(0.0 \%)$. There 
A: FLC group; 5-FU/LV + CPT-11

5 consecutive days (1-5) per week + Day 15 / month / 1 course

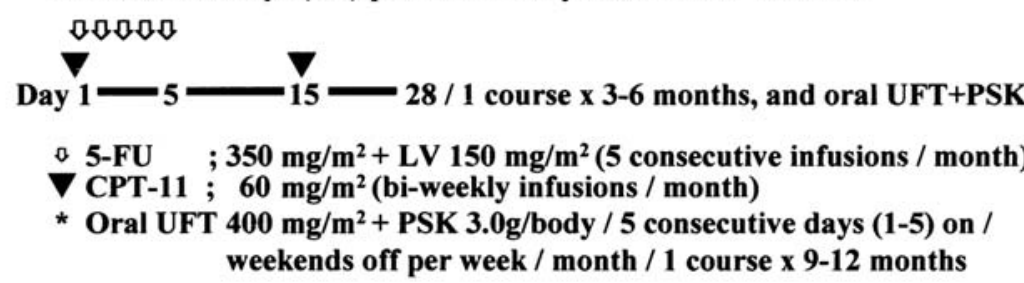

B: FDP group; 5-FU + low dose CDDP

5 consecutive days (1-5) per week / month / 1 course 0.0000

\author{
Day $1-5-15-28 / 1$ course $\times$ 3-6 months, and oral UFT+PSK* \\ a 5-FU ; $350 \mathrm{mg} / \mathrm{m}^{2}+$ CDDP $5 \mathrm{mg} / \mathrm{m}^{2}$ (5 consecutive infusions / month) \\ * Oral UFT $400 \mathrm{mg} / \mathrm{m}^{2}+$ PSK 3.0g/body / 5 consecutive days (1-5) on / \\ weekends off per week / month / 1 course $x$ 9-12 months
}

Figure 1. Postoperative outpatient adjuvant chemotherapy. (A) The FLC group was treated with a modified Machoever's regimen (5-FU at 350 mg/m² + LV at $150 \mathrm{mg} / \mathrm{m}^{2}$ x 5 consecutive days/month x 3-6 months) of monthly high-dose 5-FU/LV combined with administration of CPT-11 (60 mg/m ${ }^{2}$ every 2 weeks $\mathrm{x}$ 3-6 months) on day 1 and day 15 . This was followed by oral anticancer therapy for 1 to 1.5 years. (B) The FDP group received 5-FU (350 mg/m²) + lowdose CDDP $\left(5 \mathrm{mg} / \mathrm{m}^{2}\right.$ x 5 consecutive days/month x 3-6 months), followed by oral anticancer agents for 1 to 1.5 years.

Table I. Among hematological/non-hematological toxicities, grade 1-2 leucopenia and olfactory neuropathy (cranial-smell) were significantly more common in the NP-CRC group than in the NP-GC group $(\mathrm{p}<0.05, \mathrm{p}<0.05)$.

\begin{tabular}{|c|c|c|c|c|c|c|c|c|}
\hline \multirow{2}{*}{$\begin{array}{l}\text { Grade }(\mathrm{n}=28) \\
\text { Performance status (PS) }\end{array}$} & \multicolumn{2}{|c|}{0} & \multicolumn{2}{|c|}{$1-2$} & \multicolumn{2}{|c|}{3} & \multicolumn{2}{|c|}{4} \\
\hline & 12 & $42.9 \%$ & 14 & $50.0 \%$ & 2 & $7.1 \%$ & 0 & $0.0 \%$ \\
\hline Face scale (FS) & 4 & $14.3 \%$ & 22 & $78.6 \%$ & 2 & $7.1 \%$ & 0 & $0.0 \%$ \\
\hline Leukopenia & 16 & $57.1 \%$ & 12 & $42.9 \%{ }^{*}$ & 0 & $0.0 \%$ & 0 & $0.0 \%$ \\
\hline Anemia & 19 & $67.9 \%$ & 9 & $32.1 \%$ & 0 & $0.0 \%$ & 0 & $0.0 \%$ \\
\hline Thrombocytopenia & 26 & $92.9 \%$ & 2 & $7.1^{*}$ & 0 & $0.0 \%$ & 0 & $0.0 \%$ \\
\hline Nausea & 12 & $42.9 \%$ & 16 & $57.1 \%$ & 0 & $0.0 \%$ & 0 & $0.0 \%$ \\
\hline Vomiting & 26 & $92.9 \%$ & 2 & $7.1 \%$ & 0 & $0.0 \%$ & 0 & $0.0 \%$ \\
\hline Anorexia & 13 & $46.4 \%$ & 15 & $53.6 \%$ & 0 & $0.0 \%$ & 0 & $0.0 \%$ \\
\hline Mucositis/Stomatitis & 27 & $96.4 \%$ & 1 & $3.6 \%$ & 0 & $0.0 \%$ & 0 & $0.0 \%$ \\
\hline Taste alteration (Dysgeusia) & 26 & $92.9 \%$ & 2 & $7.1 \%$ & 0 & $0.0 \%$ & 0 & $0.0 \%$ \\
\hline Neuropathy: cranial-smell & 21 & $75.0 \%$ & 7 & $25.0 \%{ }^{*}$ & 0 & $0.0 \%$ & 0 & $0.0 \%$ \\
\hline Diarrhea & 24 & $85.7 \%$ & 4 & $14.3 \%$ & 0 & $0.0 \%$ & 0 & $0.0 \%$ \\
\hline Constipation & 23 & $82.1 \%$ & 5 & $17.9 \%$ & 0 & $0.0 \%$ & 0 & $0.0 \%$ \\
\hline Fatigue (malaise) & 21 & $75.0 \%$ & 6 & $21.4 \%$ & 1 & $3.6 \%$ & 0 & $0.0 \%$ \\
\hline Mood alteration: anxiety/Depression & 28 & $100.0 \%$ & 0 & $0.0 \%$ & 0 & $0.0 \%$ & 0 & $0.0 \%$ \\
\hline Alopecia & 28 & $100.0 \%$ & 0 & $0.0 \%$ & 0 & $0.0 \%$ & 0 & $0.0 \%$ \\
\hline Neuropathy: sensory & 27 & $96.4 \%$ & 1 & $3.6 \%$ & 0 & $0.0 \%$ & 0 & $0.0 \%$ \\
\hline Insomnia & 24 & $85.7 \%$ & 4 & $14.3 \%$ & 0 & $0.0 \%$ & 0 & $0.0 \%$ \\
\hline
\end{tabular}

Price, 1-course

Euro 586.8 (1 Euro= ¥121)

${ }^{*} \mathrm{p}<0.05$

were no significant differences between the two groups (Tables I and II). In the NP-CRC group, thrombocytopenia was grade 0 in 26 patients $(92.9 \%)$, grade 1 or 2 in 2 patients
$(7.1 \%)$, grade 3 in 0 patients $(0.0 \%)$, and grade 4 in 0 patients $(0.0 \%)$. In the NP-GC group, thrombocytopenia was grade 0 in 9 patients $(60.0 \%)$, grade 1 or 2 in 6 patients $(40.0 \%)$, 
Table II. Among hematological/non-hematological toxicities, grade 1-2 thrombocytopenia was significantly more common in the NP-GC group than in the NP-CRC group $(\mathrm{p}<0.05)$.

\begin{tabular}{|c|c|c|c|c|c|c|c|c|}
\hline \multirow{2}{*}{$\begin{array}{l}\text { Grade }(\mathrm{n}=15) \\
\text { Performance status (PS) }\end{array}$} & \multicolumn{2}{|c|}{0} & \multicolumn{2}{|c|}{$1-2$} & \multicolumn{2}{|c|}{3} & \multicolumn{2}{|c|}{4} \\
\hline & 6 & $40.0 \%$ & 8 & $53.3 \%$ & 1 & $6.7 \%$ & 0 & $0.0 \%$ \\
\hline Face scale (FS) & 0 & $0.0 \%$ & 11 & $73.3 \%$ & 4 & $26.7 \%$ & 0 & $0.0 \%$ \\
\hline Leukopenia & 13 & $86.7 \%$ & 2 & $13.3 \% *$ & 0 & $0.0 \%$ & 0 & $0.0 \%$ \\
\hline Anemia & 10 & $66.7 \%$ & 5 & $33.3 \%$ & 0 & $0.0 \%$ & 0 & $0.0 \%$ \\
\hline Thrombocytopenia & 9 & $60.0 \%$ & 6 & $40.0 \% *$ & 0 & $0.0 \%$ & 0 & $0.0 \%$ \\
\hline Nausea & 10 & $66.7 \%$ & 5 & $33.3 \%$ & 0 & $0.0 \%$ & 0 & $0.0 \%$ \\
\hline Vomiting & 12 & $80.0 \%$ & 3 & $20.0 \%$ & 0 & $0.0 \%$ & 0 & $0.0 \%$ \\
\hline Anorexia & 8 & $53.3 \%$ & 6 & $40.0 \%$ & 1 & $6.7 \%$ & 0 & $0.0 \%$ \\
\hline Mucositis/Stomatitis & 15 & $100.0 \%$ & 0 & $0.0 \%$ & 0 & $0.0 \%$ & 0 & $0.0 \%$ \\
\hline Taste alteration (Dysgeusia) & 15 & $100.0 \%$ & 0 & $0.0 \%$ & 0 & $0.0 \%$ & 0 & $0.0 \%$ \\
\hline Neuropathy: cranial-smell & 15 & $100.0 \%$ & 0 & $0.0 \% *$ & 0 & $0.0 \%$ & 0 & $0.0 \%$ \\
\hline Diarrhea & 15 & $100.0 \%$ & 0 & $0.0 \%$ & 0 & $0.0 \%$ & 0 & $0.0 \%$ \\
\hline Constipation & 14 & $93.3 \%$ & 1 & $6.7 \%$ & 0 & $0.0 \%$ & 0 & $0.0 \%$ \\
\hline Fatigue (malaise) & 9 & $60.0 \%$ & 6 & $40.0 \%$ & 0 & $0.0 \%$ & 0 & $0.0 \%$ \\
\hline Mood alteration: anxiety/depression & 15 & $100.0 \%$ & 0 & $0.0 \%$ & 0 & $0.0 \%$ & 0 & $0.0 \%$ \\
\hline Alopecia & 15 & $100.0 \%$ & 0 & $0.0 \%$ & 0 & $0.0 \%$ & 0 & $0.0 \%$ \\
\hline Neuropathy: sensory & 14 & $93.3 \%$ & 1 & $6.7 \%$ & 0 & $0.0 \%$ & 0 & $0.0 \%$ \\
\hline Insomnia & 14 & $93.3 \%$ & 1 & $6.7 \%$ & 0 & $0.0 \%$ & 0 & $0.0 \%$ \\
\hline
\end{tabular}

Price, 1-course

Euro 181.8 (1 Euro= ¥121)

*p $<0.05$

grade 3 in 0 patients $(0.0 \%)$, and grade 4 in 0 patients $(0.0 \%)$ In the NP-GC group, grade 1 or 2 thrombocytopenia was significantly more common than in the NP-CRC group $(\mathrm{p}<0.05)$ (Tables I and II). With regard to non-hematological toxicity, neuropathy (cranial-smell) was grade 0 in 21 patients (75.0\%), grade 1 or 2 in 7 patients $(25.0 \%)$, grade 3 in 0 patients $(0.0 \%)$, and grade 4 in 0 patients $(0.0 \%)$ from the NP-CRC group. In the NP-GC group, neuropathy (cranial-smell) was grade 0 in 15 patients $(100.0 \%)$, grade 1 or 2 in 0 patients $(0.0 \%)$, grade 3 in 0 patients $(0.0 \%)$, and grade 4 in 0 patients $(0.0 \%)$. In the NP-CRC group, grade 1 or 2 olfactory neuropathy was significantly more common than in the NP-GC group $(\mathrm{p}<0.05)$ (Tables I and II). No significant differences were found between the two groups with respect to other non-hematological toxicities (Tables I and II).

The total cost to the patient for 1 course was $€ 586.8$ in the NP-CRC group and $€ 181.8$ in the NP-GC group (1 Euro= 〜121) (Tables I and II).

\section{Discussion}

In patients who undergo surgery for cancers such as breast common malignancies in the US and Europe, intravenous administration of anticancer agents for a relatively long period is common. The regimens employed were developed from analysis of a large amount of accumulated data (14-16,29,30). Excluding organ-specific and hormone-dependent tumors that occur in men and women, such as prostate cancer or breast cancer, the malignant potential of NP-GC cancer is midway between that of esophageal cancer and that of colorectal cancer among digestive tract tumors $(2,4,31)$. For the treatment of colorectal cancer, intravenous administration of potent combination chemotherapy regimens, such as IFL, FOLFIRI, or FOLFOX, has a high level of evidence and is widely used around the world, including the US and Europe (14-16). In the case of esophageal cancer, a high-dose 5-FU + high-dose CDDP regimen is not only used postoperatively but also preoperatively as a neo-adjuvant therapy $(31,32)$. In Japan, the prevalence of gastric cancer is decreasing, but it is still high compared with other countries. There are few widely accepted treatment regimens based on a high level of evidence that are used overseas (25-27). We employ highdose 5-FU/low-dose CDDP as standard post-operative adjuvant therapy for NP-GC (20-22). With this regimen, treatment can be performed in a relatively short time at the outpatient clinic since hydration is unnecessary. The regimen involves 5 consecutive injections as the metronomic administration with double modulation for each modulator. There were two major issues with respect to comparison of the NP-CRC/FLC and NP-GC/FDP groups in this study.

One was the safety and tolerability of FLC, as performed routinely at our hospital, for Japanese patients who have a relatively small body size. The most popular regimen for colorectal cancer in the US and Europe, FOLFIRI, was used 
as the standard for this assessment. The CPT-11 dose was set at $50-60 \%$ of that for conventional FOLFIRI and a modified Machoever's regimen which is a high dose of 5-FU/LV for five consecutive days, was employed with modified IFL. It appears that the QOL including safety and tolerability of outpatient treatment is adequate since the mean total number of courses was 5.4. However, the cost of one course of FLCmultidrug therapy such as FOLFIRI or IFL is at least three times higher than that of FDP. The Japanese government provides a subsidy for new combinations that include molecular-targeting drugs such as angiogenesis inhibitors, but it can be assumed that the cost to the patient will increase considerably in the future based on the likely state of government finances. On the other hand, FDP treatment which is a mean of 5.1 courses was a regimen that achieved good QOL at a lower cost compared with FLC. However, NP-GC is slightly more aggressive than NP-CRC, so there is still a need to consider more potent multidrug chemotherapy including molecular targeting drugs due to the limited response rate and tumor inhibitory effect achieved with regimens such as 5-FU/LV+CDDP, FLC, and/or CPT-11+ CDDP.

When the optimum dosage for Japanese patients with a relatively smaller body size is assumed to be $50-60 \%$ of that for Westerners, the following problems arise concerning the ideal administration method. When 5-FU/LV therapy is used for colorectal cancer, the RPMI regimen which is one dose weekly for 6 weeks +2 -week washout period x 3 courses, is very popular among patients and physicians (33). This regimen only requires attendance once a week at hospital and markedly improves the QOL of patients, but rapid saturation of 5-FU occurs due to administration of a single weekly dose. Rapid administration of 5-FU induces inhibition of RNA synthesis, but the most important effect of inhibiting DNA synthesis by cancer cells does not appear to occur (34-36). Therefore, 24-h continuous infusion is recommended to induce the inhibition of DNA synthesis, but this is not appropriate for outpatient treatment because of relatively severe AEs. An alternative is five consecutive doses in one week for Machoever's regimen that achieves a relatively long continuous exposure time (28). Administration once a week for 6 weeks or administration on five consecutive days once a month probably should be available as options depending on the patient's lifestyle.

In previous years, treatment with $\mathrm{TS}-1$, a new oral anticancer agent, has become very common in Japan $(25,26)$. The sensitivity of Asians to the effects of oral anticancer agents is assumed to be higher than that of Westerners because of low expression of TS/DPD. Oral anticancer agents have the great advantage making treatment at home possible and improving QOL because frequent outpatient visits are not required, as well as having a lower cost $(26,37,38)$. However, unlike intravenous administration with confirmation by physicians and nurses, a major problem is that it remains unclear whether or not correct administration has actually occurred even when patients make entries in medication notebooks or complete questionnaires. At present, a large-scale clinical study of intravenous 5-FU/CDDP vs. oral TS-1/intravenous CDDP (FLAGS, first-line advanced gastric cancer study) after curative resection of gastric cancer is being performed in 26 Western countries, and this is expected to provide evidence about the most effective postoperative adjuvant chemotherapy for gastric cancer (25-27).

The most effective adjuvant therapy for node-positive cancer is systemic consolidation chemotherapy at an early stage postoperatively when the tumor may have a higher sensitivity $(29,30)$. Investigation of tumor sensitivity to 5FU/LV therapy at the time of systemic dispersion of circulating ONC clusters that may develop into metastases has revealed that few tumors show a high sensitivity represented by a high-TS/low-DPD level, suggesting that this regimen might be too weak $(39,40)$. To increase the potency of this regimen, addition of CPT-11 or L-OHP which are more popular in the West than in Japan could be effective with respect to interactions and potentiation by modulation (14-16). Problems related to the optimum dosage and administration schedule have already been discussed, but it is considered that tumor sensitivity to the additional drugs is more important. To obtain a survival benefit for patients, it has been reported that improvement of survival after tumor recurrence is most important $(41,42)$. In patients with a high risk of recurrence of colorectal cancer or gastric cancer patients with ONC clusters, the most effective procedure is to select an appropriate regimen for the perioperative period, which is considered to be the time when occult systemic metastasis occurs prior to detection of recurrence after curative surgery. It is recommended that multi-combination chemotherapy with a higher activity should be used 5-FU based chemotherapy for gastrointestinal cancer so that the treatment is not inadequate. In the future, more detailed studies of anticancer drug activity including ethnic differences between Asians and Westerners will be required.

\section{Acknowledgements}

This study was supported by grants from the Occult Neoplastic Cells Research and Study Group (No. 2008-5007; Tokai University Hachioji Hospital, Hachioji, Tokyo, Japan) and the Research and Study Program of Tokai University Educational System General Research Organization (No. 2007-04; Tokai University Hospital, Isehara, Kanagawa, Japan).

\section{References}

1. Knacks \& Pit falls: Surgery of the colon, rectum and anus. (2nd edition). Bunkoudou, Co., Ltd., Tokyo, 2004.

2. Guide line of large Bowel Cancer in Japan. Japanese Society for Cancer of the Colon and Rectum, Tokyo, 2005.

3. Knacks \& Pit falls: Surgery of the stomach, Bunkoudou, Co., Ltd., Tokyo, 2005.

4. Guide line of gastric cancer in Japan. (2nd edition). Japanese Gastric Cancer Association, Tokyo, 2005.

5. Japanese Classification of gastric carcinoma (13th edition), Japanese Gastric Cancer Association, Tokyo, 2005.

6. Mukai M: Occult neoplastic cells and malignant microaggregates in lymph node sinuses: Review and hypothesis. Oncol Rep 14: 173-175, 2005.

7. Mukai M, Sato S, Komatsu N, Nishida T, Shiba K, Ito I, Nakasaki $\mathrm{H}$ and Makuuchi H: Correlation between occult neoplastic cells in the lymph node sinuses and recurrence in patients with Dukes' C colorectal cancer. Oncol Rep 10: 1165-1169, 2003.

8. Mukai M, Sato S, Komatsu N, Nishida T, Shiba K, Ito I, Nakasaki $\mathrm{H}$ and Makuuchi H: Correlation between occult neoplastic cells in the lymph node sinuses and recurrence in patients with curatively resected Dukes' B colorectal cancer. Oncol Rep 10: 1177-1181, 2003. 
9. Mukai M, Sato S, Nishida T, Komatsu N, Shiba K, Nakasaki H, and Makuuchi H: Selection criteria for high risk and low risk groups of recurrence and metastasis in patients with primary colorectal cancer. Oncol Rep 10: 1753-1758, 2003.

10. Mukai M, Sato S, Nakasaki H, Saito Y, Nishiumi N, Iwasaki M Tokuda Y, Ogoshi K, Inoue H and Makuuchi H: Occult neoplastic cells in the lymph node sinuses and recurrence of primary breast, lung, esophageal and gastric cancer. Oncol Rep 11: $81-84,2004$.

11. TNM classification of malignant tumours. (6th edition). John Wiley \& Sons, Inc., New York, 2002.

12. Mukai M, Sato S, Ninomiya H, Wakui K, Komatsu N, Tsuchiya K, Tajima T, Nakasaki H and Makuuchi H: Prospective study on the recurrence/metastasis of stage II/III colorectal and gastric cancer associated with occult neoplastic cells in lymph node sinuses: Three-year interim results. Oncol Rep 16: 405-410, 2006.

13. Mukai M, Oida Y, Tajima T, Kishima K, Ninomiya H, Sato S Nakamura M, Nakasaki $\mathrm{H}$ and Makuuchi H: Alternating hepatic arterial infusion and systemic chemotherapy for stage IV colorectal cancer with synchronous liver metastasis. Oncol Rep 16: 865-870, 2006

14. Saltz LB, Cox JV, Blanke C, Rosen LS, Fehrenbacher L, Moore MJ, Maroun JA, Ackland SP, Locker PK, Pirotta N, Elfring GL and Miller L, for the Irinotecan study group: Irinotecan plus fluorouracil and leucovorin for metastatic colorectal cancer. N Engl J Med 343: 905-914, 2000.

15. Tournigand C, Achille TAE, Lledo G, Flesh M, Quinaux DM-ME Couteau C, Buyse M, Ganem G, Landi B, Colin P, Louvet C and De Gramont A: FOLFIRI followed by FOLFOX 6 or the reverse sequence in advanced colorectal cancer: A randomized GERCOR study. J Clin Oncol 22: 229-237, 2004.

16. Colucci G, Gebbia V, Paoletti G, Giuliani F, Caruso M, Gebbia N, Cartenì G, Agostara B, Pezzella G, Manzione L, Borsellino N, Misino A, Romito S, Durini E, Cordio S, Seri MD, Lopez M and Maiello E: Phase III randomized trial of FOLFIRI versus FOLFOX 4 in the treatment of advanced colorectal cancer: A multicenter study of Gruppo Oncologico Dell'Italia Meridionale. J Clin Oncol 23: 4866-4875, 2005.

17. Iwamoto S, Kimoto M, Mure T, Onuma E, Yamamoto Y, Iki K, Yoshida K, Tadaoka Y, Majima T, Kawasaki S, Kubozoe T and Tsunoda T: Sequential chemotherapy with methotrexate and 5fluorouracil for advanced gastric cancer. Jpn J Cancer Chemother 25: 541-546, 1998.

18. Kim R, Murakami S, Ohi Y, Inoue H, Yoshida $\mathrm{K}$ and Toge T: A phase II trial of low dose administration of 5-fluorouracil and cisplatin in patients with advanced and recurrent gastric cancer. Int J Oncol 15: 921-926, 1999.

19. Chen JS, Liu HE, Wang CH, Yang TS, Wang HM, Liau CT, Chang WC and Lin YC: Weekly 24-H infusion of high-dose 5fluorouracil and leucovorin in patients with advanced gastric cancer. Anti-Cancer Drugs 10: 355-359, 1999.

20. Enjoji A and the Nagasaki digestive organ cancer chemotherapy study group: Combination chemotherapy of 5-fluorouracil and low-dose Cisplatin in advanced and recurrent gastric cancer: a multicenter retrospective study in Nagasaki, Japan. Anticancer Res 22: 1135-1140, 2002 .

21. Terashima M, Irinoda $T$, Kawamura $H$, Takagane $A$, Abe $K$, Oyama K, Fujiwara H, Saito K and Gotoh M: Intermittent FLDP: 24-h infusion of 5-FU on day 1, 3 and 5 combined with low-dose cisplatin on days 1-5 for gastric cancer, and its pharmacologic and kinetic rationale. Cancer Chemother Pharmacol 51: 240-246, 2003

22. Kim R, Tanabe K, Inoue $H$ and Toge $T$ : Mechanisms of antitumor action in protracted infusion of low dose 5-fluorouracil and cisplatin in gastric carcinoma. Int J Oncol 20: 549-555, 2002.

23. Sugimachi K, Maehara Y, Horikoshi N, Shimada Y, Sakata Y, Mitachi Y, Taguchi T and the S-1 Gastrointestinal Cancer Study Group: An early phase II study of oral S-1, a newly developed 5-fluorouracil derivative for advanced and recurrent gastrointestinal cancers. Oncology 57: 202-210, 1999.

24. Koizumi W, Kurihara M, Nakano S, Hasagawa K, for the S-1 Cooperative Gastric Cancer Study Group: Phase II study of S-1, a novel oral derivative of 5-fluorouracil, in advanced gastric cancer. Oncology 58: 191-197, 2000.

25. Koizumi W, Tanabe S, Saigenji K, Ohtsu A, Boku N Nagashima F, Shirao K, Matsumura Y and Gotoh M: Phase I/II study S-1 combined with cisplatin in patients with advanced gastric cancer. Br J Cancer 89: 2207-2212, 2003.
26. Sakuramoto S, Sasako M, Yamaguchi T, Kinoshita T, Fujii M, Nashimoto A, Furukawa H, Nakajima T, Ohashi Y, Imamura H, Higashino M, Yamamura Y, Kurita A and Arai K for the ACTS-GC Group: Adjuvant chemotherapy for gastric cancer with S-1, an oral fluoropyrimidine. N Engl J Med 357: 1810-1820, 2007.

27. Koizumi W, Narahara H, Hara T, Takagane A, Akiya T, Takagi M, Miyashita K, Nishizaki T, Kobayashi O, Takiyama W, Toh Y, Nagaie T, Takagi S, Yamamura Y, Yanaoka K, Orita H and Takeuchi M: S-1 plus cisplatin versus S-1 alone for firstline treatment of advanced gastric cancer (SPIRITS trial): A phase III trial. Lancet Oncol 9: 215-221, 2008.

28. Machover D, Schwarzenberg L, Goldschmidt E, Tourani JM, Michalski B, Hayat M, Dorval T, Misset JL, Jasmin C, Maral R and Mathe G: Treatment of advanced colorectal and gastric adenocarcinomas with 5-FU combined with high-dose folinic acid: a pilot study. Cancer Treat Rep 66: 1803-1807, 1982.

29. National Institutes of Health Consensus Development Panel. National Institutes of Health consensus development conference statement: adjuvant therapy for breast cancer, November 1-3, 2000. J Natl Cancer Inst 93: 979-989, 2001

30. Goldhirsch A, Glick JH, Gelber RD, Coates AS and Senn H-J: Meeting highlights: International consensus panel on the treatment of primary breast cancer. J Clin Oncol 19: 3817-3827, 2001.

31. Guide line of esophageal cancer in Japan, The Japanese Society for Esophageal Diseases, Tokyo, 2003.

32. Knacks \& Pit falls: Surgery of the esophagus, Bunkoudou, Co., Ltd., Tokyo, 2003.

33. Wolmark N, Rockette H, Fisher B, Wickerham DL, Redmond C, Fisher ER, Jones J, Mamounas EP, Ore L, Petrelli NJ, Spurr CL, Dimitrov N, Romond EH, Sutherland CM, Kardinal CG, DeFusco PA and Jochimsen P: The benefit of leukovorinmodurated fluorouracil as post operative adjuvant therapy for primary colon cancer: Results from National Surgical Adjuvant Breast and Bowel Project Protocol C-03. J Clin Oncol 11: $1879-1887,1993$.

34. Duschinsky R, Pleven E and Heidelberger C: The synthesis of 5-fluoropyrimidines. J Am Chem Soc 79: 4559-4560, 1957.

35. Heidelberger C, Leibman KC, Harbers E, and Bhargava PM: The comparative utilization of uracil-2-c14 by liver, intestinal mucosa, and Flexner-jobling carcinoma in the rat. Cancer Res 17: 399-404, 1957

36. Lokich JJ, Ahlgren JD, Gullo JJ, Philips JA and Fryer JG: A prospective randomized comparison of continuous infusion of fluorouracil with a conventional bolus schedule in metastatic colorectal carcinoma: A mid-Atlantic Oncology Program study. J Clin Oncol 17: 425-432, 1989.

37. Mukai M, Moriya H, Himeno S, Oida Y, Mukoyama S, Nishi T, Nakasaki H, Sato S and Makuuchi H: Efficacy of oral UFT plus leucovorin therapy for colon cancer with ovarian and multiple liver metastases: report of two cases. Oncol Rep 8: 1079-1083, 2001.

38. Mukai M, Hinoki T, Tajima T, Sato S, Nakasaki H, Ogoshi K and Makuuchi $\mathrm{H}$ : Complete remission after combination chemotherapy for stage IV gastric cancer with peritoneal dissemination and liver matastases; case report. Ann Cancer Res Therap 11: 169-181, 2003

39. Mukai M, Sato S, Ninomiya H, Wakui K, Tsuchiya K Komatsu N, Nakasaki H and Makuuchi H: Recurrence and 5-FU sensitivity of stage III/Dukes' C colorectal cancer with occult neoplastic cells in lymph node sinuses. Oncol Rep 14: 1165-1169, 2005.

40. Mukai M, Sato S, Ninomiya H, Wakui K, Tsuchiya K, Komatsu N, Nakasaki H and Makuuchi H: Sensitivity to CPT11 and platinum derivatives of stage III/Dukes' $\mathrm{C}$ colorectal cancer with occult neoplastic cells in lymph node sinuses. Oncol Rep 17: 1027-1032, 2007.

41. Feinstein AR, Sosin DM and Wells CK: The Will Rogers phenomenon: Stage migration and new techniques as a source of misleading statistics for survival in cancer. N Engl J Med 312: 1604-1608, 1985.

42. Bunt AMG, Hermans J, Smit VTHBM, van de Velde CJH, Fleuren GL and Bruijn JA: Surgical/pathologic stage migration confounds comparisons of gastric cancer survival rates between Japan and Western countries. J Clin Oncol 13: 19-25, 1995. 